\title{
Holographic and Speckle Interferometry
}

A Discussion of the Theory, Practice and Application of the Techniques

\section{ROBERT JONES and CATHERINE WYKES}

'The book will appeal most to postgraduate research students, but other workers in this field will find it a most comprehensive laboratory manual of the theories involved (and a series of appendices summarize the necessary mathematics and background material).... Just why ESPI has not been more popular remains a mystery, for it offers the kind of speedy and comprehensive techniques of analysis that industry usually seeks. If the excellent exposition of the subject in this book doesn't do a lot to promote ESPI, it is difficult to know what would.' Elliot Robertson, The Times Higher Education Supplement

\section{Interferometry \\ $£ 29.50 \mathrm{net} / \$ 54.50$}

\section{Second Edition}

\section{W. S. STEEL}

The new edition of this popular textbook has been extensively revised and enlarged to reflect the phenomenal growth in laser techniques and applications of recent years. The many possible applications of interferometry are examined, and the author presents a lucid exposition of the common theory that underlies them all.

$£ 35.00$ net $/ \$ 69.50$

\section{CAMBRIDGE UNIVERSITY PRESS}

\section{The Journal of Plasma Physics}

Editor. J. P. Dougherty,

Lecturer in Applied Mathematics, University of Cambridge

The Journal of Plasma Physics publishes research into the behaviour and uses of ionized media Both theoretical and experimental papers are published, including numerical investigations of theoretical problems. It also carries some book reviews.

Special Offer on Back Volumes' Subscriptions

We are offering a $33 \frac{1}{3} \%$ discount on all back volumes of The Journal of Plasma Physics. The offer is current until 30th June 1983 and is subject to availability.

Volumes 1.28 (1967-1982) usual rate $£ 60.00$ per volume

SPECIAL OFFER RATE £40.00 PER VOLUME

Volumes 1.4 were each issued in four parts, later volumes in three parts.

An index to Volumes 1-20 is free to subscribers.

Subscription

Volume 29: February, April and June 1983 Volume 30: August, October and December 1983

$£ 67.50 / \$ 177$ per volume $£ 135 / \$ 354$ per year

Single parts: $£ 25 / \$ 66.50$ Individuals rate (1983) $£ 67.50 / \$ 177$

For further information please contact Journals Publicity at the address below. North American enquiries should be sent to Journals Promotion, Cambridge University Press, 32 East 57 th Street, New York, N.Y. 10022, U.S.A. 


\section{Information for Contributors}

1. Manuscripts must be written in English. All manuscripts will be referred to acknowledged experts in the subject. Only those receiving favourable recommendations from the referees will be accepted for publication. Manuscripts may be sent to any Board member, any Associate Editor or the Editor.

2. The typescript should be double spaced, on one side of good grade paper, allowing a reasonable left-hand margin. An original and two copies should be submitted with the author's full postal address, position and affiliations.

3. The title and section headings should highlight the significant points. A short abstract should precede the main text.

4. One copy of photographs, prints or transparencies of good quality and unmarked should be submitted. Where lines or lettering are to appear on the photograph, an additional print should be supplied appropriately marked. Each should have, lightly written on the back, the author's name, the figure number and an indication of which is the top of the picture.

5. One copy of each line diagram should be submitted at approximately twice final size and unlettered. Diagrams must be drawn in indian ink on plain white or transparent paper. A second copy should be supplied with lettering included. The author's name and the figure number should be written on this copy.

6. Tables should be typewritten on separate sheets. Avoid, where possible, very wide tables.

7. References should be cited in the text, according to the Harvard (Author/date system), but giving the last name of the author(s) followed by a comma and the year of publication e.g. DICKEN \& LLOYD 1979; FLETCHER 1978. If there is more than one work by an author in a given year, then label them alphabetically within each year, e.g. HALL, 1967a. The full references should be typed, double-spaced, on a separate sheet of paper at the end of the article. They must include the names and initials of all the authors, the year of publication, the full title of the article (or book), the standard abbreviated name of the journal.

SHEERIN, J. P. \& ONG, R. S. B. 1980 J. Plasma Phys. 24, 157.

WHITTAKER, E. T. \& WATSON, G. N. 1962 A Course of Modern Analysis, p. 36. Cambridge University Press, Cambridge.

8. Correction to proofs should be restricted to printers' errors only. Authors are entitled to 25 offprints of their article free of charge. Additional offprints may be purchased if they are ordered on the form sent with the proofs. 


\section{LASER AND PARTICLE BEAMS}

Volume 1 Part 3 August 1983

\section{CONTENTS}

S. Kawata and K. Niu: Numerical simulations for intense light-ion beam propagation in a channel under the influence of plasma inertia 219

R. G. Evans: A simple model of ion beam heated ICF targets 231

I. V. Alexandrova, N. G. Basov, A. E. Danilov, Yu. A. Mikhailov, G. V. Sklizkov and S.

I. Fedotov: The effect of small-scale perturbations on the brightness of laser radiation in laser fusion experiments 241

S. Eliezer and A. Ludmirsky: Double layer (DL) formation in laser-produced plasma 251

J. Handke, S. A. H. Rizvi and B. Kronast: A laser plasma interaction model for the conditions of stimulated Brillouin backscattering model experiments 271

P. Lalousis and H. Hora: First direct electron and ion fluid computation of high electrostatic fields in dense inhomogeneous plasmas with subsequent nonlinear laser interaction 283

Wang Runwen: Instabilities of bounded plane plasma irradiated by a high intensity laser beam 305

C. W. Mendel, Jr., D. B. Seidel and S. E. Rosenthal: A simple theory of magnetic insulation from basic physical considerations 311

M. M. Novak: Electromagnetic waves in a high density field 321

Book review and conference report 331

\section{FORTHCOMING PAPERS}

N. G. Basov, A. E. Danilov, M. P. Kalashnikov, B. V. Kruglov, Yu. A. Mikhailov, A. V. Rode, G. V. Sklizkov and S. I. Fedotov: Investigation of a high aspect ratio shell at the laser installation DELFIN-1

M. Nambu: A new laser effect in plasma turbulence based on bremsstrahlung instability

G. J. Tallents: A numerical investigation of laser pressure effects in underdense plasmas

J. A. Kunc and M. A. Gundersen: A fundamental theory for high power thyratrons II. The production of atomic hydrogen and positive ions

C. Yamanaka, S. Nakai, K. Mima, H. Nishimura and Y. Kitagawa: Review of cannonball target implosion

(C) Cambridge University Pṛess 1983

Cambridge University Press, The Pitt Building, Trumpington Street, Cambridge CB2 1RP; 32 East 57th Street, New York, N.Y. 10022 